ARTIGO

\title{
Determinantes acadêmicos da retenção no Ensino Superior
}

\author{
Ana Cléssia Pereira Lima de Araújo ${ }^{a}$ \\ Francisca Zilania Mariano ${ }^{b}$ \\ Celina Santos de Oliveira c
}

\section{Resumo}

Esta pesquisa teve por objetivo verificar possíveis determinantes da retenção nas instituições federais brasileiras, analisando por áreas de conhecimento dos cursos presenciais. Para tanto, identificaram-se os alunos na situação de retido, dentre os concludentes, considerando a base de dados obtida do Censo de Educação Superior para o ano de 2016. A partir de três níveis ordenados do período de retenção, a aplicação de um modelo de escolha multinomial ordenado permitiu obter as seguintes conclusões: em geral, considerando uma retenção acima de dois anos, características como ser do sexo masculino, ou da raça branca, ou participante das políticas afirmativas ou ingressante por meio do Enem contribuem de forma negativa sobre a probabilidade de retenção. Além disso, destaca-se que a ampliação de bolsas e de apoio assistencial das instituições se mostrou relevante para conter a retenção em todas as áreas de conhecimento.

Palavras-chave: Retenção Discente. Logit Ordenado. Educação Superior.

\section{Introdução}

$\mathrm{O}$ atraso na conclusão de um curso superior representa uma perda social, visto que há gastos desnecessários tanto a nível individual como coletivo, fazendo com que não haja o devido retorno do investimento na Educação Superior. Do ponto de vista individual, ao demorar a concluir o curso, o indivíduo está deixando de receber os benefícios proporcionados pela diplomação, como seus possíveis rendimentos como graduado. Além disso, os estudantes que adiam a Graduação estão contribuindo para uma má alocação dos recursos das universidades e

\footnotetext{
a Universidade Federal do Ceará, Fortaleza, CE, Brasil.

b Universidade Federal do Ceará, Sobral, CE, Brasil.

c Universidade Federal do Ceará, Sobral, CE, Brasil.
} 
também impedem o aumento da quantidade de profissionais qualificados no mercado de trabalho.

Segundo o Censo de Educação Superior, entre 2006 e 2016, o número de matrículas na Educação Superior aumentou $62,8 \%$, com uma média anual de $5,0 \%$ de crescimento. Porém, a quantidade de alunos concluintes, em 2014, por exemplo, era de $44,7 \%$ nas instituições públicas, apontando altas taxas de evasão e de retenção.

Nesse âmbito, refere-se à retenção como o processo que decorre da permanência prolongada do estudante universitário na instituição que ultrapassa o período regular de integralização do curso. Esse fenômeno é um dos fatores que interfere nos recursos financeiros que são repassados às Instituições Federais de Ensino Superior (Ifes), pois integra o cálculo do Total de Alunos Equivalentes de Graduação (Taeg) ${ }^{1}$. Desse modo, as Ifes que possuem o maior quantitativo de alunos equivalentes, terão um maior recebimento de recursos, enquanto que, quanto maior a porcentagem de alunos que não se formam no tempo regular, menor será o Taeg. Logo, haverá uma redução do financiamento recebido. Dessa forma, ao considerar esse índice para a destinação de recursos, surge uma maior preocupação para incentivar a taxa de sucesso do discente.

A partir de dados da Diretoria de Estatísticas Educacionais do Instituto Nacional de Estudos e Pesquisas Educacionais (Deed/Inep), certifica-se uma estimativa de investimento público direto por estudante universitário de $\mathrm{R} \$ 23.215,00$, para o ano de 2015. Essa quantia seria o gasto médio de se manter um aluno por mais um ano na universidade, demonstrando uma grande problemática em mitigar a retenção discente.

Na literatura, diversos trabalhos procuram investigar os fatores que impactam a evasão no Ensino Superior (BAGGI; LOPES, 2011; PRESTES; FIALHO, 2018; SACCARO; FRANÇA; JACINTO, 2016; SILVA FILHO et al., 2007), porém, a investigação sobre a retenção é secundária, em que não se identificam trabalhos sobre os determinantes acadêmicos da retenção nas instituições de Ensino Superior público no Brasil.

Logo, este trabalho procura contribuir com a literatura ao fornecer uma análise dos determinantes acadêmicos relacionados ao discente, ao curso e à instituição que influenciam a retenção nas instituições federais de Ensino Superior público.

Principal indicador para fins de análise dos custos de manutenção das Ifes, nas rubricas referentes ao orçamento de custeio e capital. 
Além disso, procurou-se considerar as especificidades das diferentes áreas de conhecimento, de forma a identificar se os determinantes variam entre elas. Para tanto, fez-se uso dos dados do Censo de Educação Superior, referente ao ano de 2016 e estimou-se um modelo econométrico politocômico ordenado.

Assim, o escopo desse artigo está organizado em mais quatro seções. A próxima refere-se a um levantamento teórico acerca da retenção no Ensino Superior. Em seguida, é apresentado a metodologia adotada. Logo após, expõe-se os resultados estimados e, por fim discorre-se as considerações finais.

\section{Revisão de Literatura}

\subsection{Retenção no Ensino Superior}

No Brasil, a retenção é conceituada como permanência prolongada do aluno na universidade, em que o discente continua em situação de matriculado no curso de Graduação por um tempo maior do que o planejado pelo currículo da instituição (LIMA JÚNIOR et al., 2019; VASCONCELOS; SILVA, 2011).

Segundo Lamers et al. (2017), a retenção ocorre por motivo de suspensão, cancelamento ou trancamento de matrícula ou repetência, fazendo com que o estudante necessite de um maior período para finalizar o curso.

De acordo com Campelo e Lins (2008) e Mainier et al. (2006), o atraso no término da graduação pode levar o aluno a evasão. Assim, essas duas definições estão bastantes associadas, evidenciando a importância da redução da retenção para combater os antecedentes que ocasionam a desistência permanente do estudante. Em vista disso, os fatores determinantes da retenção estão estritamente ligados aos fatores que levam à evasão.

Estudos da literatura brasileira evidenciam que fatores internos e externos à instituição determinam a retenção. Dentre os fatores externos, ressaltam-se as dificuldades dos estudantes em conciliar a carga horária das aulas e do trabalho (VANZ et al., 2016). Na pesquisa de Vasconcelos e Silva (2011), o perfil do aluno retido é aquele que possui idade acima da média dos universitários (31 a 50 anos), possui filhos e tem a responsabilidade de sustento da família. Em relação aos fatores internos, destacam-se a falta de apoio financeiro e a falta ou restrição de programas acadêmicos (auxílios financeiros, bolsas e monitoria). Esses fatores também estão associados aos cursos, exemplificando, citam-se as dificuldades nas disciplinas, metodologias dos professores e a falta de prática do curso (SILVA, 2017). 
Da mesma forma, a retenção é considerada uma preocupação notável para os formuladores de políticas em outros países. Conforme Vidales (2009), a evasão e a retenção, classificadas como um fracasso escolar, têm sido questões preocupantes na maioria dos países, desde os europeus até os latino-americanos, sendo considerados fenômenos complexos e multidimensionais que constituem uma problemática educativa e social.

$\mathrm{Na}$ literatura internacional, os fatores que influenciam na retenção discente na Educação Superior estão voltados ao mercado de trabalho e ao comprometimento do aluno durante a Graduação. A necessidade de trabalhar em tempo parcial para financiar os estudos, as perspectivas de empregos ruins e taxa de desemprego elevada reduzem o estímulo para a formação regular (AINA; CASSALONE, 2011; BRUNELLO; WINTER-EBMER, 2003). Além disso, segundo Brunello e Winter-Ebmer (2003), o atraso na Graduação é substancialmente maior em países europeus com proteção mais rigorosa do emprego e que a Graduação de faculdades percebidas como de maior qualidade demanda maior tempo, talvez por causa do currículo mais exigente.

Ferrão e Almeida (2018) reforçam que os alunos que são admitidos na primeira opção de curso têm maior probabilidade de concluir a Graduação em comparação aos alunos não admitidos em sua primeira escolha, afirmando que o efeito da admissão na primeira opção de curso parece captar a motivação e o comprometimento do aluno em terminar o curso com sucesso. Ademais, aqueles estudantes que não declararam repetência na Educação Básica têm maior probabilidade de sucesso no Ensino Superior, reforçando o que Ferrão (2015) afirma, que a repetição precoce é um forte preditor de repetição tardia.

Nessa perspectiva, English e Umbach (2016) acrescentam que o sucesso do estudante na Educação Superior está relacionado ao desempenho acadêmico, ao processo de admissão ao Ensino Superior, compreendendo a escolha da instituição e do curso.

Lima Júnior et al. (2019) colocam que a retenção é vinculada à problemas que podem ser resolvidos pela própria instituição, tais como as oportunidades de aprendizagem, a oferta de disciplinas, a concepção curricular dos cursos, o acolhimento da diversidade, entre outros.

É possível, ainda, que fatores anteriores à inserção do Ensino Superior venham a influenciar a retenção. Por exemplo, a qualidade dos docentes na Educação Básica. Como Bauer, Cassettari e Oliveira (2017) afirmam, um dos fatores 
para melhoria da qualidade da Educação em geral está nas políticas públicas direcionadas aos docentes, uma vez que esses compõem o fator direto que influencia a aprendizagem dos alunos.

Em vista disso, muitos pesquisadores discorrem possíveis políticas para a redução da retenção. Tais políticas estão associadas à ampliação ou à criação de bolsas, visando ao apoio financeiro, maior integração ao ambiente acadêmico, informação e motivação dos estudantes sobre as possibilidades de carreira em sua futura área de atuação (BARCELOS JÚNIOR, 2015). Essas políticas também estão ligadas ao aprendizado. Pereira (2013) propôs um sistema de programas de suporte acadêmico para melhorar o aprendizado e o desempenho acadêmico, como tutoria, orientação acadêmica e monitorias.

Araújo e Leite (2014) e Saccaro, França e Jacinto (2016) enfatizam a importância dos programas de bolsas permanência na Educação Superior brasileira, que visam a auxiliar financeiramente os estudantes de Ensino Superior que, na média, são menos abastados e, portanto, mais propensos à evasão e também à retenção.

Andriola e Araújo (2018) destacam a relevância da seleção de indicadores educacionais pelos gestores, como método de obter informações e ter um diagnóstico situacional da instituição, estabelecendo um planejamento estratégico para adoção de ações e de projetos

Nessa mesma linha, Donoso-Díaz, Iturrieta e Traverso (2018) alertam que devido à rápida e massiva expansão do Ensino Superior na América Latina nos últimos anos, preocupações vêm sendo geradas, como o aumento das taxas de retenção, principalmente se considerar a mudança de perfil dos ingressantes. Os autores destacam a importância de estratégias e de ações para minimizar as taxas de retenção. Uma das mais importantes abordadas está no desenvolvimento de Sistemas de Alerta Precoce que são definidos como a criação de sistemas de alertas automatizados que buscam detectar o aluno que possuem risco de atraso ou de abandono, antecipando, assim, a ocorrência desses fatores. Dessa forma, é possível adotar medidas que possam minimizar as condições ruins dos alunos e influir na sua decisão de não atrasar ou de abandonar o curso.

É sobre esse contexto que o presente artigo vem contribuir com a literatura, identificar fatores acadêmicos que podem determinar a retenção no Ensino Superior, embasando, assim, a criação dos Sistemas de Alerta Precoce das instituições de Ensino Superior. 


\section{Metodologia}

\subsection{Modelo econométrico}

Tendo em vista o objetivo proposto, adotou-se uma metodologia com um modelo econométrico do tipo logit ordenado ${ }^{2}$, que possui uma variável de resposta politocômica, ou seja, a variável dependente $\mathrm{Y}$ possui mais de duas respostas possíveis e essas apresentam um ordenamento. A escolha desse modelo é justificada pelo objetivo de identificar a quantidade do tempo de retenção dos alunos, considerando os seguintes casos ordenados: alunos que não se encontram na condição de retenção, aqueles que estão retidos entre 6 e 18 meses e os que estão vinculados fora do prazo previsto há mais de 18 meses.

Assim, o modelo assume a seguinte estrutura geral:

$Y_{i}=\beta_{i}^{\prime} X_{i}+\varepsilon_{i}$, para $\mathrm{i}=1, \ldots, \mathrm{n}$

Onde Y representa uma variável latente observada na forma discreta mediante uma classificação, assumindo a seguinte estrutura:

$\mathrm{Y}=\left\{\begin{array}{l}1, \text { se } Y^{*} \leq \propto_{1} \\ 2, \text { se } \propto_{1}<Y^{*} \leq \propto_{1} \\ \cdot \\ \cdot \\ J, \text { se } \propto_{j-1}<Y_{i}^{*} \leq \alpha_{j}\end{array}\right.$

Sendo $\beta_{i}$ o vetor de K parâmetros a serem estimados, $X_{i}$ o conjunto de variáveis explicativas e o erro aleatório, $\varepsilon_{i}$.

Para determinar os limites do intervalo da variável latente em (2), calculou-se a variável dependente retenção em anos de acordo com a equação (3). Nessa equação, foi considerado o ano de conclusão como sendo 2016, em que esse é subtraído pelo ano de ingresso no curso, observando o semestre e a duração do curso. Com isso, estabeleceu-se a situação do vínculo do aluno, se está retido ou não, e, no caso positivo, há quanto tempo apresenta-se nessa situação.

Retenção $=$ Ano de conclusão - Ano de ingresso - Carga Horária do Curso

2 A estimação foi realizada por máxima-verossimilhança. 
Em seguida, computou-se a retenção em meses, mapeando assim a escala da variável dependente:

$Y=\left\{\begin{array}{l}0, \text { se Retenção }<6 \text { meses }^{3} \\ 1, \text { se } 6 \text { meses } \leq \text { Retenção } \leq 18 \text { meses } \\ 2, \text { se Retenção }>18 \text { meses }\end{array}\right.$

Assim, o modelo permite a estimação de probabilidades de $\mathrm{Y}$ em assumir um ranking de valores, no caso 0,1 e 2 e encontrar os efeitos marginais das variáveis.

\subsection{Base de dados}

Para avaliar as variáveis que afetam a retenção nos cursos de graduação das Ifes, utilizaram-se dados disponibilizados pelo Inep, o Censo de Educação Superior e o Índice Geral dos Cursos (IGC), referentes ao ano de 2016. O IGC, segundo o Ministério da Educação (MEC), é um indicador de Qualidade da Educação Superior composto pela média ponderada envolvendo as notas dos cursos de graduação, os Conceitos Capes e o número de matrículas dos cursos de Pós-Graduação. Sendo assim, o IGC reflete a qualidade dos cursos que, por sua vez, poderá afetar de forma positiva na diminuição das taxas de retenção das instituições de Ensino Superior. Foram consideradas apenas as Ifes ${ }^{4}$ e seus cursos presenciais, sendo realizados alguns filtros na amostra, tais como: selecionou-se somente alunos em situação de concluinte ${ }^{5}$ e ingressantes no curso por meio do Enem ou de vestibular.

\footnotetext{
3 Os alunos que se formaram antes do período ótimo estão inseridos na mesma categoria dos alunos não retidos, pois a variável retenção seria um valor negativo, logo, menor do que seis meses. Esses alunos representam apenas $6 \%$ da amostra.

4 Universidades e institutos federais.

5 Embora haja uma perda no número de observações, optou-se por considerar apenas os concluintes para que se pudesse calcular exatamente o tempo de retenção. Esse tempo exato só pode ser determinado após a conclusão do curso. Se não considerarmos essa restrição, poderíamos colocar na mesma categoria um discente que está 12 meses (por exemplo) retido em 2016 (período da observação), mas que não irá se formar naquele período (ou seja, seu tempo de retenção no curso será superior a 12 meses), com discentes que ficaram retidos de fato 12 meses, pois já estavam concluindo em 2016. Os autores testaram um modelo binário (retido ou não em 2016) considerando todos os alunos, não apenas os concluintes, porém, esse modelo também apresenta limitações, pois estaríamos considerando, em uma mesma categoria, discentes com retenção de 6 meses, com discentes com mais de 24 meses, por exemplo. Dos resultados das estimações, observaram-se semelhanças nos sinais e nas significâncias das variáveis. Embora com essa nova estimativa, optamos em continuar a análises considerando apenas os concluintes, a fim de calcularmos o tempo exato de retenção.
} 
A relação entre abandono e retenção é bastante considerada na literatura (CUNHA; TUNES; SILVA, 2001; LOTUFO et al., 1998; MAGALHÃES; REDIVO, 1998; MAZZETTO; BRAVO; CARNEIRO, 2002; RIBEIRO, 2005). Numa regressão de abandono, omitir a retenção poderá gerar viés nas estimativas (omissão de variáveis), pois a retenção pode levar ao abandono, porém, a volta não é observada. Logo, acredita-se que não se têm elevadas perdas em não considerar os alunos que abandonaram na análise. Embora, exista uma relação entre tempo de retenção de abandono, os alunos podem abandonar o curso por diferentes fatores, tais como: descontentamento com horários das disciplinas, falta de cursos noturnos, impossibilidade de trabalhar e estudar ao mesmo tempo (LOTUFO et al., 1998; MACHADO, MELO FILHO; PINTO, 2005; MAGALHÃES; REDIVO, 1998; MAZZETTO; BRAVO; CARNEIRO, 2002; PACHECO et al., 2001; VELOSO; ALMEIDA, 2002), mau relacionamento professor-aluno (CUNHA; TUNES; SILVA., 2001; VELOSO; ALMEIDA, 2002), pouca integração social à universidade (POLYDORO, 2000; TINTO, 1997), expectativas não correspondidas e falta de informações sobre curso e profissão (CUNHA; TUNES; SILVA, 2001; LOTUFO et al., 1998; MACHADO; MELO FILHO; PINTO., 2005; MAGALHÃES; REDIVO, 1998; PACHECO et al., 2001; RIBEIRO, 2005), problemas financeiros (LOTUFO et al., 1998; MACHADO; MELO FILHO; PINTO, 2005; PACHECO et al., 2001; PALMA; PALMA; BRANCALEONI, 2005; POLYDORO, 2000; RIBEIRO, 2005), dentre outros, que não necessariamente tempo de retenção.

Com isso, não considerar os alunos que abandonaram não significa, necessariamente, que haverá uma perda significativa de alunos retidos com alto tempo de evasão, pois o desligamento costuma ser maior nos anos iniciais do curso (MAGALHÃES; REDIVO, 1998; PALMA; PALMA; BRANCALEONI, 2005; PRADO, 1990; RIBEIRO, 2005; SBARDELINI, 1997; VELOSO; ALMEIDA, 2002). No modelo apresentado pela equação (1), a variável dependente é a retenção discente, classificada de acordo com a ordenação presente na equação (4) e as variáveis explanatórias utilizadas referem-se às características dos alunos, à localização da instituição e ao ambiente acadêmico, identificadas no Quadro 1. 
Quadro 1 - Descrição das variáveis explicativas

\begin{tabular}{|c|c|}
\hline Variáveis & Descrição \\
\hline \multicolumn{2}{|r|}{ Aluno } \\
\hline Idade & anos de idade \\
\hline Sexo & $1=$ se masculino; 0 = se feminino \\
\hline Cor_Raça & $1=$ se branca; 0 = se não branca \\
\hline \multicolumn{2}{|r|}{ Localização } \\
\hline Capital* $^{*}$ & 1 = s e a IFES está localizada na capital; 0 = se está localizada no interior \\
\hline Região_ne & 1 = se a IFES está localizada na região Nordeste; 0 = caso contrário \\
\hline Região_s & 1 = se a IFES está localizada na região Sul; 0 = caso contrário \\
\hline Região_se & 1 = se a IFES está localizada na região Sudeste; 0 = caso contrário \\
\hline Região_co & 1 = se a IFES está localizada na região Centro-Oeste; 0 = caso contrário \\
\hline \multicolumn{2}{|r|}{ Acadêmicas } \\
\hline Cotista & $\begin{array}{l}1 \text { = se o discente ingressou por meio de reserva de vagas de cunho } \\
\text { étnico, social, renda familiar, egresso de escola pública e outros; } \\
\quad 0=\text { ampla concorrência }\end{array}$ \\
\hline Bolsista & $\begin{array}{l}1 \text { = se o discente participa de algum programa de bolsas remunerado } \\
\text { de estágio não obrigatório, monitoria, pesquisa e extensão; } \\
0 \text { = caso contrário }\end{array}$ \\
\hline Ing_enem & $\begin{array}{c}1=\text { se o discente ingressou por seleção via Enem; } 0=\text { se ingressou por } \\
\text { meio do vestibular }\end{array}$ \\
\hline Apoio_social & $\begin{array}{l}1 \text { = se o discente recebe algum auxílio na forma de moradia, transporte, } \\
\text { alimentação, material didático e bolsas (trabalho/permanência); } \\
\qquad 0=\text { caso contrário }\end{array}$ \\
\hline Tipo_escola & $\begin{array}{c}1 \text { = se o discente cursou o ensino médio em escola pública; } \\
0 \text { = se cursou em escola particular }\end{array}$ \\
\hline Turno_mat** & 1 = se o curso de graduação é matutino; 0 = caso contrário \\
\hline Turno_not & 1 = se o curso de graduação é noturno; 0 = caso contrário \\
\hline Turno_integ & 1 = se o curso de graduação é integral; 0 = caso contrário \\
\hline $\begin{array}{l}\text { Grad_ } \\
\text { bacharelado*** }\end{array}$ & 1 = se o curso de graduação é do tipo bacharelado; 0 = caso contrário \\
\hline Grad_licenciatura & 1 = se o curso de graduação é do tipo licenciatura; 0 = caso contrário \\
\hline IGC & Índice Geral dos Cursos \\
\hline
\end{tabular}

Fonte: Elaboração própria (2018)

* Informa se o local de oferta do curso presencial está localizado na capital

** Destaca-se que dentre os alunos existem também aqueles que estão matriculados em cursos de turno vespertino

*** Destaca-se que dentre os alunos existem também aqueles que estão matriculados em cursos de grau tecnológico 


\section{Resultados}

\subsection{Análise Descritiva}

A Tabela 1 apresenta as estatísticas descritivas das variáveis empregadas neste estudo. Primeiro, apresentam-se as estatísticas descritivas da amostra total e, posteriormente, são apresentados os dados agrupados para cada uma das oito áreas gerais dos cursos de Graduação ${ }^{6}$. A amostra obtida é composta por 66.019 alunos; em relação à situação final deles, apenas 17.576 (26,62\%) colaram grau no tempo previsto, 30.387 (46,03\%) ficaram retidos entre um a três semestres e $18.056(27,35 \%)$ ficaram retidos por um período maior que três semestres.

Observa-se que, em média, os alunos estão retidos no período de tempo dentro do segundo intervalo exposto no conjunto de equações (4), que significa um tempo de 6 a 18 meses. Ademais, todas as áreas de cursos estão próximas a esse intervalo, encontrando-se uma média moderadamente maior nos cursos ligados à área de humanas, seguida pela área das engenharias e uma média menor nos cursos da área de saúde.

Ao analisar o perfil do aluno, percebe-se que a maioria é do sexo masculino (57,62\%), a média de idade é de 26 anos e $55,16 \%$ consideram-se brancos. Em relação à localização geográfica das Ifes, aproximadamente $63,62 \%$ encontramse nas capitais brasileiras e, em maioria, estão localizadas no Nordeste (29,84\%) e no Sudeste $(28,54 \%)$.

Quanto ao recebimento de auxílio financeiro, apenas $13 \%$ dos estudantes eram beneficiados com bolsas e em torno de $18 \%$ recebiam algum tipo de apoio social. A maior parte das bolsas está direcionada para os cursos de saúde, com 19,10\%, e de ciências, matemática e computação com 16,29\%.

Analisando acerca dos cursos da amostra, em geral, prevalecem o turno integral $(53,35 \%)$ e do tipo bacharelado (71,39\%). Esses dominam os cursos, exceto os ligados à Educação, que são, em maioria, do tipo licenciatura. Evidencia-se também que as áreas que apresentam melhores indicadores de qualidade, de acordo com o IGC, são ligadas às ciências humanas e à saúde, seguidas por ciências sociais e matemática.

6 O tamanho da amostra por área de conhecimento é de 14.459 (Educação); 2.475 (Humanidades e Artes); 14.524 (Ciências Sociais, Negócios e Direito); 7.194 (Ciências, Matemática e Computação); 10.544 (Engenharia, Produção e Construção); 4.828 (Agricultura e Veterinária); 10.403 (Saúde e Bem-estar) e 1.592 (Serviços). 


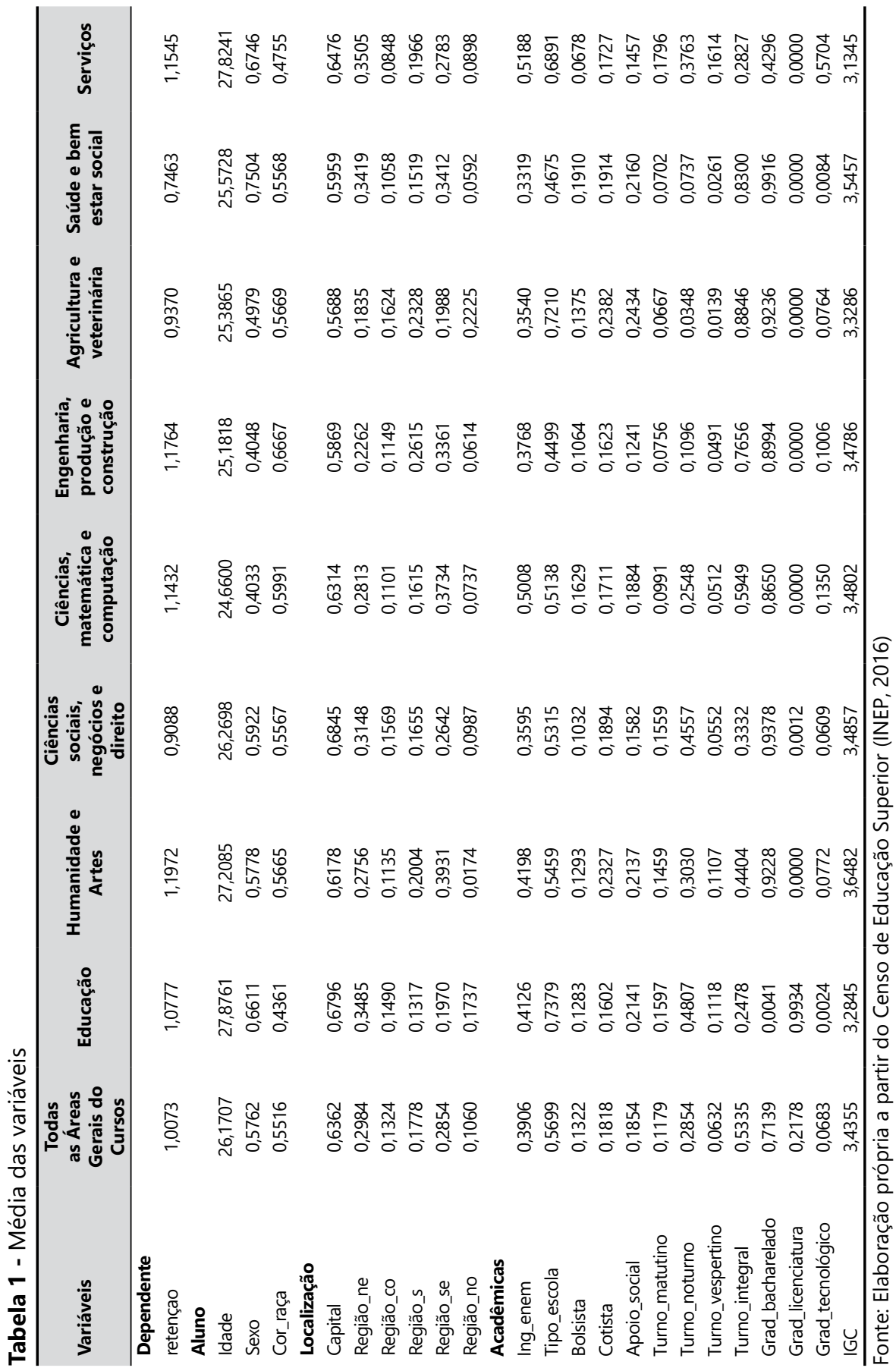




\subsection{Resultados econométricos}

Em modelos de escolha ordenada, os sinais e as magnitudes dos coeficientes não são diretamente interpretáveis, sendo necessário computar os efeitos marginais para interpretar de forma significante o modelo. $\mathrm{O}$ efeito marginal mostra $\mathrm{o}$ impacto nas probabilidades específicas por mudança de unidade no regressor. Esse impacto das variáveis explicativas sobre a probabilidade de ocorrência do tempo de retenção, descritos em três intervalos, encontra-se na Tabela 2.

As estimativas para todas as áreas de conhecimento do perfil do aluno em retenção elevada mostram que o estudante nessa situação é mais velho e do sexo feminino, exceto o grupo de saúde, que apontou efeito marginal positivo, significando que existe uma elevação de $0,95 \%$ na probabilidade de os homens serem estabelecidos na terceira situação e uma redução de $2,37 \%$ de incluir-se na primeira situação. Além disso, o aluno autodeclarado de cor branca, quando esta variável se mostra estatisticamente significante, possui uma redução na probabilidade de retenção na terceira categoria. Exemplifica-se isso na área de ciências sociais e de saúde, em que há uma diminuição de $2,97 \%$ e $0,90 \%$, respectivamente, da probabilidade de o estudante encontrar-se na terceira condição.

Dentre esses resultados, a relação positiva entre o aumento da probabilidade de retenção e a idade era esperado. Indivíduos que possuem uma idade maior propendem a ter que sustentar a família, possuir um emprego e ter um horário de trabalho incompatível com os estudos, reforçando as investigações feitas por Vanz et al. (2016), Vasconcelos e Silva (2011) e Silva (2017), o que certamente dificulta o tempo destinado para as atividades acadêmicas, aumentando a probabilidade de permanecer na faculdade por um tempo maior que o previsto.

Em superioridade nas áreas de conhecimento, o aluno que frequenta uma instituição da capital apresenta uma redução na probabilidade de maiores períodos de retenção. Porém, as ciências humanas indicaram resultado contrário: o efeito marginal para a terceira categoria foi positivo, resultando que um aluno da área de humanas da capital tem um aumento de $6,41 \%$ da probabilidade de incluir-se na terceira situação de retenção e uma redução de $3,77 \%$ da probabilidade de não estar retido. 


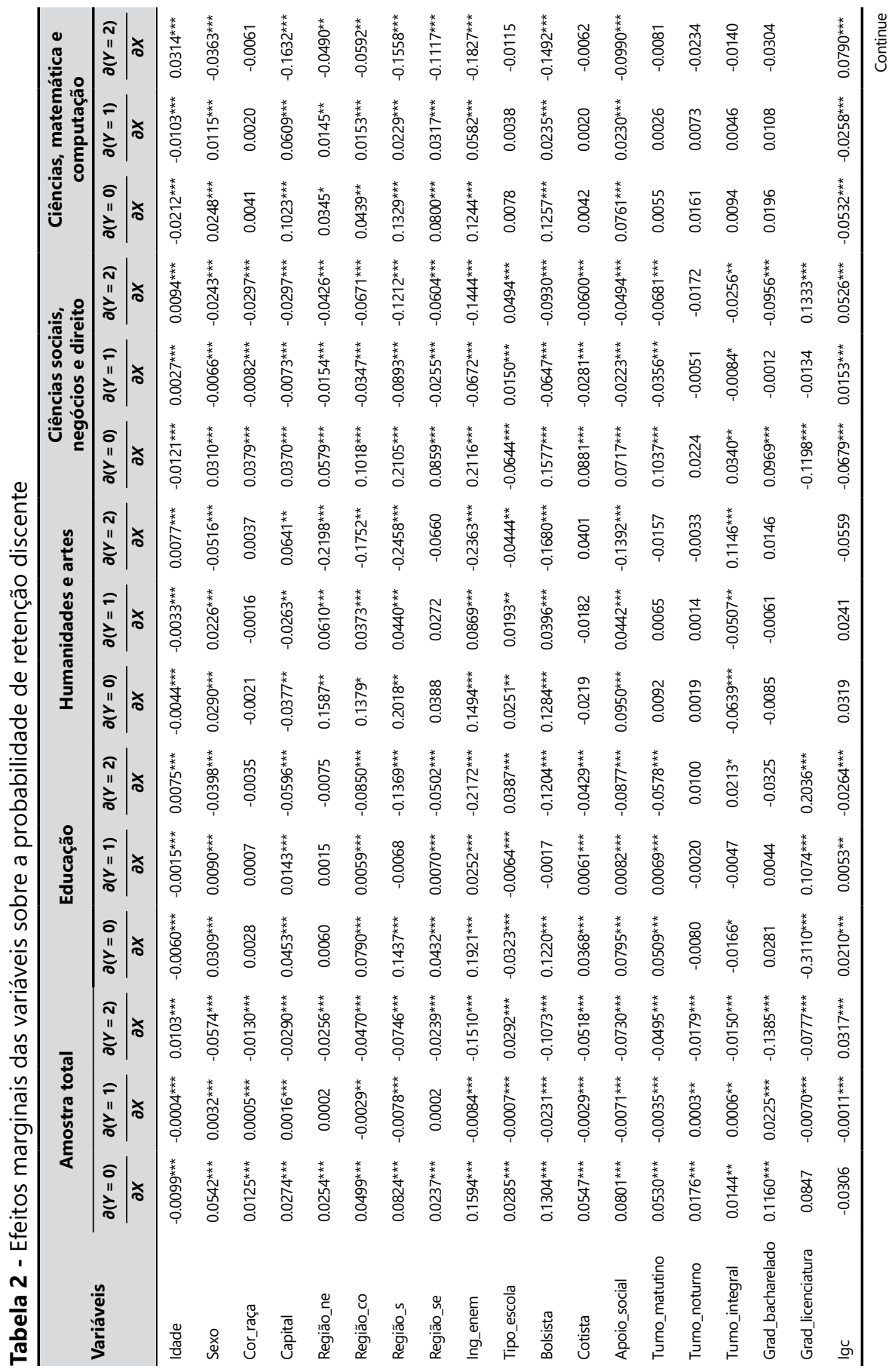




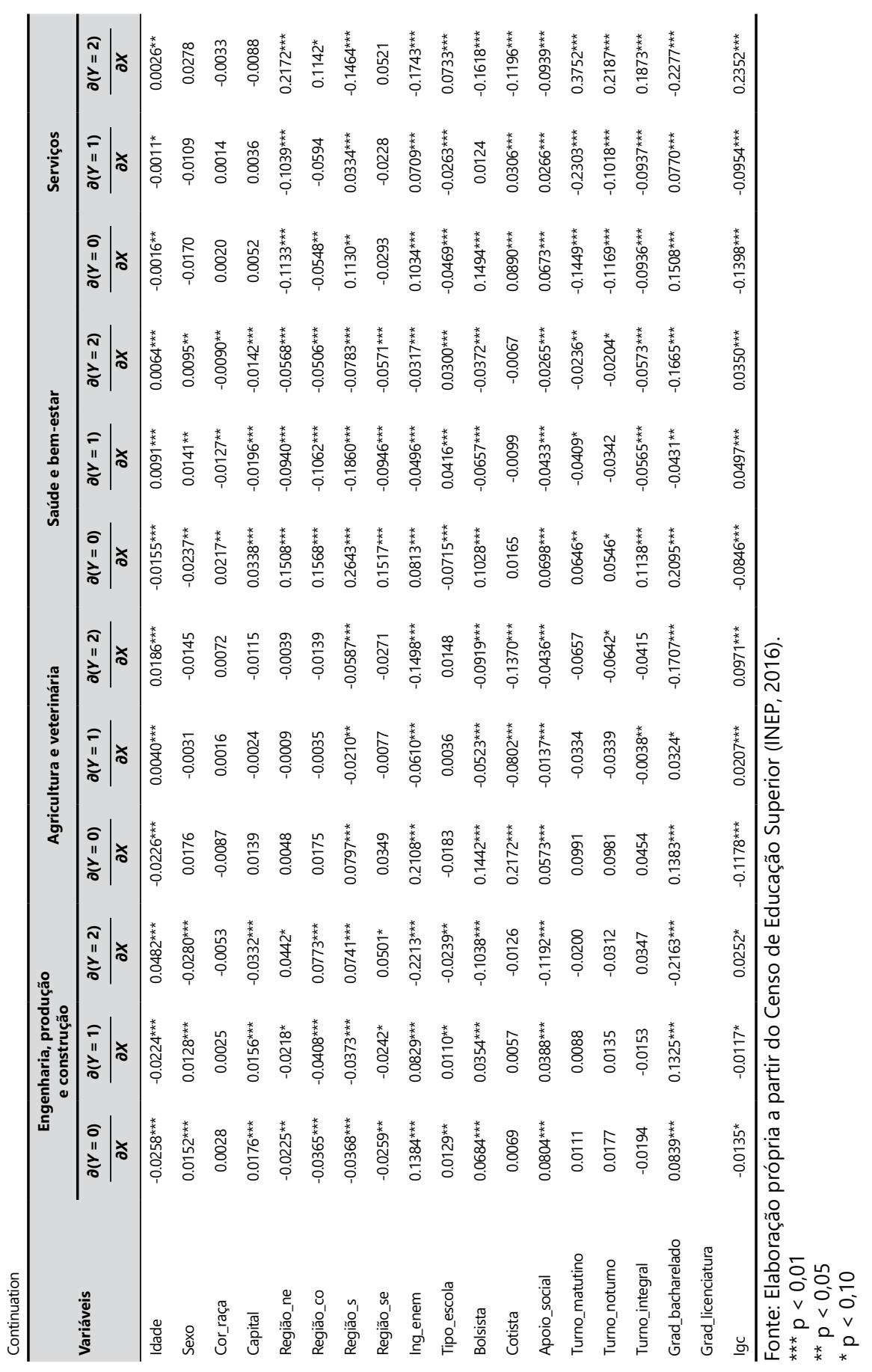


Em continuidade, se o estudante frequenta um curso da área de serviços no Nordeste, esse possui um aumento da probabilidade de estar retido na terceira categoria (21,72\%). Enquanto que, se o aluno estuda na área de engenharias do Centro-Oeste ou do Sul possui uma elevação de $7,73 \%$ e 7,41\%, respectivamente, da probabilidade de situar-se no terceiro intervalo de retenção. Por conseguinte, caso o aluno frequente um curso na área da Educação no Sudeste, esse apresenta um aumento da probabilidade de retenção na terceira categoria de 5,02\%.

Em todas as áreas, o universitário que ingressou na graduação via Enem tem uma redução da probabilidade de atrasar a conclusão do curso. Em relação aos alunos advindos do ensino médio em escola pública, esses possuem uma elevação na probabilidade de encontrarem-se no terceiro nível de retenção, excluindo-se os cursos de engenharias e humanas, que apresentaram uma diminuição de 2,39\% e 4,44\% da probabilidade de o estudante estar em um nível elevado de retenção. No que se refere ao aluno cotista, em todas as áreas que apresentou significância estatística, aponta uma diminuição da probabilidade de estar na terceira categoria e uma adição de estar na primeira categoria.

Os fatores referentes às políticas assistenciais nas Ifes apresentaram-se relevantes como mecanismo de auxílio aos universitários na obtenção do diploma de Graduação para todas as áreas. Tendo em conta que o aluno beneficiário de algum tipo de programa de bolsa ou de auxílio financeiro tem menores chances de ficar retido. (PEREIRA et al., 2015; SILVA, 2017).

Verifica-se que o turno matutino apresentou relação positiva com a probabilidade de retenção elevada nos cursos do grupo de serviços $(37,52 \%)$, enquanto que os turnos integral e noturno revelaram aumento da probabilidade de retenção na área de humanas, $11,46 \%$ e $21,87 \%$, respectivamente.

No que se refere ao grau dos cursos, o grau de bacharelado indicou diminuição na probabilidade do aluno se inserir no terceiro intervalo de retenção na maioria dos cursos, exceto nos cursos de humanas. Por motivos de colinearidade, os cursos de licenciatura foram considerados somente nas áreas de Educação e ciências sociais, ressaltando que esse grau demonstrou efeito marginal com sinal positivo na última categoria, apontando a existência, nessas áreas, de uma maior probabilidade de os estudantes atrasarem a diplomação caso o curso seja do tipo licenciatura.

Considerando o IGC das instituições, esse apresenta-se com efeito marginal positivo na terceira ordenação de retenção, exceto na área de Educação. Tal 
resultado possivelmente pode estar associado ao estudo de Brunello e WinterEbmer (2003), que afirmam que a graduação de universidades consideradas como de maior qualidade demanda maior tempo para conclusão, talvez por causa do currículo mais exigente.

\section{Conclusão}

Este trabalho visa a contribuir com a literatura ao identificar possíveis determinantes acadêmicos associados à retenção discente nas Ifes, assim como verificar os fatores que podem contribuir para sua redução, levando-se em consideração a variação desses fatores para cada grupo de conhecimento dos cursos de graduação.

A fim de alcançar o objetivo proposto, extraíram-se informações do Censo de Educação Superior de 2016 e estimaram-se as regressões logísticas ordenadas e os efeitos marginais, permitindo, assim, analisar as variáveis que aumentam ou reduzem a probabilidade de o aluno estar em atraso na diplomação.

Percebe-se que houve similaridades em relação aos impactos dos fatores para cada área geral, todavia ressalta-se que algumas variáveis demonstraram unanimidade quanto aos seus efeitos. A idade manteve-se positivamente relacionada à retenção em todos os grupos, perfazendo a literatura bibliográfica no que diz respeito ao estudante que possui família e obrigações e que tem que lidar com os custos de oportunidade, dispondo de um tempo reduzido para realizar suas atividades e concluir sua formação acadêmica. Também, cita-se que o ingresso pelo Enem permaneceu de forma negativa em todas as áreas dos cursos, evidenciando sua importância como forma de seleção à entrada dos estudantes nas Ifes.

Os fatores com maior magnitude estão ligados ao apoio financeiro e à realização de atividades acadêmicas, mantendo-se negativo em relação ao atraso na conclusão, evidenciando que os estudantes, muitas vezes, enfrentam dificuldades financeiras que influenciam na sua decisão de trancar o curso e não o concluir no tempo regular.

Desta forma, é fundamental implementar políticas institucionais que levem em conta a dimensão desse problema para a sociedade, no sentido de inserir os alunos de forma participativa na comunidade acadêmica, buscando um acompanhamento presente durante o tempo da Graduação dos estudantes para procurar os motivos de retenção e auxiliá-los em melhores decisões, visando a alcançar o sucesso desses e, portanto, a eficiência da própria instituição. 


\section{Academic determinants of retention in Higher Education}

\section{Abstract}

This research aimed to verify possible determinants of retention in Brazilian federal institutions, analyzing by areas of knowledge of the presential courses. For this, students were identified in the retention situation, among the conclusive ones, considering the database obtained from the Census of Higher Education for the year 2016. Through three levels ordered of the retention period, the application of an ordered multinomial choice model allowed to obtain the following conclusions: in all the areas of knowledge, increasing age is a determinant that rises the probability of retention of students, whereas if the student is male, white race, participant of affirmative policies and incoming by Enem is less likely to be withheld. In addition, it should be pointed out that the expansion of scholarships and assistance from institutions has proved to be relevant to contain retention in all areas of knowledge.

Keywords: Student Retention. Logit Ordered. College Education.

\section{Determinantes académicos de la retención en la Educación Superior}

\section{Resumen}

Esta investigación tuvo como objetivo verificar posibles determinantes de la retención en las instituciones federales brasileñas, analizando por áreas de conocimiento de los cursos presenciales. Para ello, se identificó a los alumnos en la situación de retenido, entre los concluyentes, considerando la base de datos obtenida del Censo de Educación Superior para el año 2016. A partir de tres niveles ordenados del periodo de retención, la aplicación de un modelo de elección multinomial ordenado permitió llegar a las siguientes conclusiones: en general, considerando una retención superior a dos años, características como ser del sexo masculino, o ser de raza blanca, o participantes en políticas positivas o ingresante a través de Enem contribuyen negativamente a la probabilidad de retención. Además, se destaca que la ampliación de becas y el apoyo asistencial de las instituciones resultó relevante para contener la retención en todas las áreas del conocimiento.

Palabras clave: Retención Discente. Logit Ordenado. Educación Universitaria. 


\section{Referências}

AINA, C.; CASALONE, G. Does time-to-degree matter? The effect of delayed graduation on employment and wages. AlmaLaurea Working Papers, Bologna, n. 38, Sep. 2011.

ANDRIOLA, W. B.; ARAÚJO, A. C. Uso de indicadores para diagnóstico situacional de Instituições de Ensino superior. Ensaio: Avaliação e Politicas Públicas em Educação, Rio de Janeiro, v. 26, n. 100, p. 645-663, jul./set. 2018. https://doi.org/10.1590/s0104-40362018002601062

ARAÚJO, J. C. F.; LEITE, L. S. Avaliação da política de apoio ao estudante desenvolvida pela UNIRIO: o Projeto de Bolsa Permanência. Ensaio: Avaliação e Políticas Públicas em Educação, Rio de Janeiro, v. 22, n. 84, p. 777-806, jul./set. 2014. https://doi.org/10.1590/S0104-40362014000300009

BAGGI, C. A. S.; LOPES, D. A. Evasão e avaliação institucional no ensino superior: uma discussão bibliográfica. Avaliação: Revista da Avaliação da Educação Superior (Campinas), v. 16, n. 2, p. 355-374, jul. 2011. https://doi.org/10.1590/S1414-40772011000200007

BARCELOS JÚNIOR, A. Retenção discente nos cursos de graduação do centro universitário do norte do espírito santo implantados a partir do REUNI. Dissertação (Mestrado em Gestão Pública) - Centro de Ciências Jurídicas e Econômicas, Universidade Federal do Espírito Santo, Vitória, 2015.

BAUER, A.; CASSETTARI, N..; OLIVEIRA, R. P. Políticas docentes e qualidade da educação: uma revisão da literatura e indicações de política. Ensaio: Avaliação e Políticas Públicas em Educação, Rio de Janeiro, v.25, n. 97, p. 943-970, out./dez., 2017. https://doi.org/10.1590/s0104-40362017002501010

BRUNELLO, G.; WINTER-EBMER, R. Why do students expect to stay longer in college? Evidence from Europe. Economics

Letters, Amsterdam, v. 80, n. 2, p. 247-253, Aug. 2003. https://doi.org/10.1016/S0165-1765(03)00086-7

CAMPELLO, A. V. C.; LINS, L. N. Metodologia de análise e tratamento da evasão e retenção em cursos de graduação de instituições federais de ensino superior. In: ENCONTRO NACIONAL DE ENGENHARIA DE PRODUÇÃO, 28., 2008, Rio de Janeiro. Anais [...] Rio de Janeiro: ABEPRO, 2008. p. 1-13. Disponível em: http://www.abepro.org.br/biblioteca/ enegep2008_TN_STO_078_545_11614.pdf. Acesso em: ago. 2018. 
CUNHA, A. M.; TUNES, E.; SILVA, R. R. Evasão do curso de química da Universidade de Brasília: a interpretação do aluno evadido. Química Nova, São Paulo, v. 24, n. 2, p. 262-280, mar./abr. 2001. https://doi.org/10.1590/S0100-40422001000200019

DONOSO-DÍAZ, S.; ITURRIETA, T. N.; TRAVERSO, G. D. Sistemas de Alerta Temprana para estudiantes en riesgo de abandono de la Educación Superior. Ensaio: Avaliação e Políticas Públicas em Educação, Rio de Janeiro, v. 26, n. 100, p. 944-967, jul/set. 2018. https://doi.org/10.1590/s0104-40362018002601494

ENGLISH, D.; UMBACH, P. D. Graduate school choice: an examination of individual and institutional effects. Review of Higher Education, Baltimore, v. 39, n. 2, p. 173-211, Dec. 2016. https://doi.org/10.1353/rhe.2016.0001

FERRÃO, M. E. Tópicos sobre retenção em Portugal através do PISA: qualidade e equidade. Arquivos Analiticos de Políticas Educativas, Tempe, v. 23, n. 114, p. 1-22, jan. 2015.

FERRÃO, M. E.; ALMEIDA, L. S. Multilevel modeling of persistence in higher education. Ensaio: Avaliação e Politicas Públicas em Educação, Rio de Janeiro, v. 26, n. 100, p. 664-683, jul/set. 2018. https://doi.org/10.1590/s0104-40362018002601610

INSTITUTO NACIONAL DE ESTUDOS E PESQUISAS EDUCACIONAIS ANÍSIO TEIXEIRA - INEP. Censo da Educação Superior 2016: notas estatísticas. Brasília, DF, 2016. Disponível em: http://download.inep.gov.br/ educacao_superior/censo_superior/documentos/2016/notas_sobre_o_censo_ da_educacao_superior_2016.pdf. Acesso em: jun. 2018.

LAMERS, J. M. S. et al. Retenção e evasão no ensino superior público: estudo de caso em um curso noturno de odontologia. Educação em Revista, Belo Horizonte, v. 33, e154730, 2017. https://doi.org/10.1590/0102-4698154730

LIMA JUNIOR, P. et al. Taxas longitudinais de retenção e evasão: uma metodologia para estudo da trajetória dos estudantes na Educação Superior. Ensaio: Avaliação e Políticas Públicas em Educação, Rio de Janeiro, v. 27, n. 102, p. 157-178, jan./mar. 2019. https://doi.org/10.1590/s0104-40362018002701431

LOTUFO, A. D. P et al. Evasão e repetência na FEIS/UNESP: análise e resultados. In: CONGRESSO BRASILEIRO DE ENSINO DE ENGENHARIA (COBENGE), 26. 1998, São Paulo. Anais[...] São Paulo: Abenge, 1998. p. 185-203. 
MACHADO, S. P.; MELO FILHO, J. M.; PINTO, A. C. A evasão nos cursos de graduação de química: uma experiência de sucesso feita no Instituto de Química da Universidade Federal do Rio de Janeiro para diminuir a evasão. Química Nova, São Paulo, v. 28, supl. 10, p. S41-43, nov./dez. 2005. https://doi.org/10.1590/S0100-40422005000700008

MAGALHÃES, M.; REDIVO, A. Re-opção de curso e maturidade vocacional. Revista da ABOP, Porto Alegre, v. 2, n. 2, p. 7-28, 1998.

MAINIER, F. B. et al. A contribuição da disciplina de introdução à engenharia química no diagnóstico da evasão. Ensaio: Avaliação e Políticas Públicas em Educação, Rio de Janeiro, v. 14, n. 51, p. 261-277, abr./jun. 2006. https://doi.org/10.1590/S0104-40362006000200008

MAZZETTO, S. E.; BRAVO, C. C.; CARNEIRO, S. Licenciatura em química da UFC: perfil sócio-econômico, evasão e desempenho dos alunos. Química Nova, São Paulo, v. 25, n. 6B, p. 1204-1210, nov./dez. 2002. https://doi.org/10.1590/S0100-40422002000700024

PACHECO, I. C. et al. Orientação profissional no $3^{\circ}$ grau:(Re) pensando possibilidades. In: SIMPÓSIO BRASILEIRO DE ORIENTAÇÃO VOCACIONAL E OCUPACIONAL, 4., 2001, São Paulo. Anais[...] São Paulo: Vetor, 2001. p. 29-37

PALMA, A. M. P. V.; PALMA, S. P. V.; BRANCALEONI, A. P. L. Prevenção à evasão no ensino superior: necessária implementação de orientação profissional a graduandos em desligamento. In: LASSANCE, M. C. P. et al. (org.). Intervenção e compromisso social: orientação profissional teoria e técnica. São Paulo: Vetor, 2005. p. 303-317.

PEREIRA, A. S. Retenção discente nos cursos de graduação presencial da UFES. Dissertação (Mestrado em Gestão Pública) - Centro de Ciências Jurídicas e Econômicas, Universidade Federal do Espírito Santo, Vitória, 2013.

PEREIRA, A. S. et al. Fatores relevantes no processo de permanência prolongada de discentes nos cursos de graduação presencial: um estudo na Universidade Federal do Espírito Santo. Ensaio: Avaliação e Políticas Públicas em Educação, Rio de Janeiro, v. 23, n. 89, p. 1015-1039, out./dez. 2015. https://doi.org/10.1590/S0104-40362015000400009

POLYDORO, S. A. J. O trancamento de matrícula na trajetória acadêmica do universitário: condições de saída e de retorno à instituição. Tese (Doutorado em Educação) - Faculdade de Educação, Universidade Estadual de Campinas, Campinas, 2000. 
PRADO, F. D. Acesso e evasão de estudantes na graduação: a situação do curso de física da USP. Tese (Doutorado em Educaçao) - Faculdade de Educação, Universidade de São Paulo, São Paulo., 1990

PRESTES, E. M. T; FIALHO, M. G. D. Evasão na educação superior e gestão institucional: o caso da Universidade Federal da Paraíba. Ensaio: Avaliação de Políticas Públicas de Educação, Rio de Janeiro, v. 26, n. 100, p. 869-89, jul./set. 2018. https://doi.org/10.1590/s0104-40362018002601104

RIBEIRO, M. A. O projeto profissional familiar como determinante da evasão universitária-um estudo preliminar. Revista Brasileira de Orientação Profissional, São Paulo, v. 6, n. 2, p. 55-70, dez. 2005.

SACCARO, A.; FRANÇA, M. T. A.; JACINTO, P. A. Retenção e evasão no ensino superior brasileiro: uma análise dos efeitos da bolsa permanência do PNAES. In: ENCONTRO NACIONAL DE ECONOMIA, 46., 2016, Rio de Janeiro. Anais[...] Niterói: Anpec, 2016. p. 1-19. Disponível em: https://www.anpec.org.br/encontro/2016/submissao/files_I/i12-707be73e0530 4f27eb9f18ae5d235c9d.pdf. Acesso em: jun. 2018.

SBARDELINI, E. T. B. A re-opção de curso na Universidade Federal do Paraná. Tese (Doutorado em Saúde Mental) - Faculdade de Medicina de Ribeirão Preto, Universidade de São Paulo, Ribeirão Preto, 1997.

SILVA, G. S. Retenção e evasão no ensino superior no contexto da expansão: o caso do curso de engenharia de alimentos da UFPB. Dissertação (Mestrado em Políticas Públicas, Gestão e Avaliação da Educação Superior) - Centro de Educação, Universidade Federal da Paraíba, João Pessoa, 2017.

SILVA FILHO, R. L. L. et al. A evasão no ensino superior brasileiro. Cadernos de Pesquisa, São Paulo, v. 37, n. 132, p. 641-659, set./dez. 2007. https://doi.org/10.1590/S0100-15742007000300007

TINTO, V. Classrooms as communities: exploring the educational character of student persistence. Journal of Higher Education, Columbus, v. 68, n. 6, p. 599-623, Dec. 1997. https://doi.org/10.2307/2959965

VANZ, S. A. S. et al. Evasão e retenção no curso de Biblioteconomia da UFRGS. Avaliação: Revista de Avaliação da Educação Superior (Campinas), Sorocaba, v. 21, n. 2, p. 541-568, jul. 2016. https://doi.org/10.1590/S1414-40772016000200012 
VASCONCELOS, A. L. F. S.; SILVA, M. N. Uma investigação sobre os fatores contribuintes na retenção dos alunos no curso de ciências contábeis em uma IFES: um desafio à gestão universitária. Registro Contábil, Maceió, v. 2, n. 3, p. 21-34, 2011.

VELOSO, T. C. M. A.; ALMEIDA, E. P. Evasão nos cursos de graduação da Universidade Federal de Mato Grosso, campus universitário de Cuiabá: um processo de exclusão. Série Estudos, Campo Grande, n. 13, p. 133-148, jan./jun. 2002.

VIDALES, S. El fracaso escolar en la educación media superior. El caso del bachillerato de una universidad mexicana. REICE. Revista Iberoamericana sobre Calidad, Eficacia y Cambio en Educación, v. 7, n. 4, p. 320- 341, 2009.

\section{Informações sobre as autoras}

Ana Cléssia Pereira Lima de Araújo: Mestranda em Economia Rural pela Universidade Federal do Ceará. Contato: anaclessia.lima@alu.ufc.br

iD https://orcid.org/0000-0003-1659-8070

Francisca Zilania Mariano: Doutora em Economia pela Universidade Federal do Ceará. Professora do Departamento de Economia e Finanças da mesma universidade. Membro e Fundadora do educLAB. Contato: zilania@ufc.br

iD https://orcid.org/0000-0002-1282-8812

Celina Santos de Oliveira: Doutora em Economia pela Universidade Federal da Paraíba. Professora do Departamento de Economia e Finanças da Universidade Federal do Ceará. Contato: oli.celina@gmail.com

iD https://orcid.org/0000-0002-2293-3915 